\title{
Interacción entre la Granodiorita Pinchal y el Xenolito kilométrico de Cerro Negro, Sierra de Moreno, Región de Antofagasta, Chile
}

\author{
Hans Niemeyer \\ Marcelo Nava \\ Iván Soto
}

Departamento de Ciencias Geológicas, Universidad Católica del Norte, Casilla

1280, Antofagasta, Chile

hansn@ucn.cl

marcelonavaardiles@msn.com

isoto@ucn.cl

RESUMEN

\begin{abstract}
Se estudian los procesos asociados a la interacción entre la Granodiorita Pinchal (GP) y el Xenolito kilométrico de Cerro Negro (XKCN). La GP se enfrió durante el Carbonífero Superior en tanto que la edad del XKCN no se conoce hasta el momento. EI XKCN se presenta en la cúpula de la GP. Está formado por una secuencia estratificada de rocas córneas de $600 \mathrm{~m}$ de areniscas, pelitas y conglomerados córneos. Al microscopio, las areniscas se caracterizan por el desarrollo de una matriz de fábrica granoblástica con minerales recristalizados de, plagioclasa, cuarzo, biotita, actinolita, hornblenda y granate. Estos minerales constituyen asociaciones mineralógicas generadas comprendidas dentro del rango de temperatura de 320 a $550^{\circ} \mathrm{C}$. La GP es de composición predominantemente granodiorítica y, en menor proporción, monzogranítica. En el flanco occidental del XKCN, la GP presenta facies porfírica, en tanto que en su contacto oriental este plutón exhibe facies fanerítica equigranular. En el borde occidental, el contacto del XKCN con la GP corresponde a una zona de cizalle dúctil desarrollada en la facies porfírica de la GP. En el borde oriental, el contacto se caracteriza por asimilación, presencia de xenolitos de metasedimentitas e inyecciones de material granítico. En el borde oriental del XKCN, el contacto se caracteriza por asimilación, presencia de xenolitos de metasedimentitas e inyecciones de material granítico. Este último se caracteriza por presentar estructuras megascópicas tales como plegamiento sinclinal y deflexión de capas en su parte septentrional, que se asocian a la caída gravitacional del XKCN en el magma de la GP por el mecanismo de 'stoping'. En cambio, la actitud homoclinal del XKCN en su parte meridional, con aumento de manteo de las capas entre el borde occidental y el borde oriental, se interpreta como debido a la extensión, relacionada con el basculamiento hacia el sureste durante su caída. La foliación y lineaciones metamórficas dentro del XKCN representan fábricas penetrativas dúctiles originadas durante esta deformación. Además, en el XKCN se observan venas ptigmáticas, pliegues y 'boudinage'. También afloran estructuras de carácter frágil-dúctil como grietas de tensión. Sobre la base del análisis de 'strain' en conglomerados deformados se estableció una deformación coaxial con desarrollo de un elipsoide de 'strain' prolado. Se trata de tectonitas LS. Se reconstruye la historia del proceso de 'stoping' del XKCN, desde su desprendimiento de la roca de caja, metamorfismo, deformación y, finalmente, hundimiento y detención dentro de la masa del plutón. Con el caso de estudio abordado en el presente trabajo se demuestra que el 'stoping' magmático puede darse en gran escala en la cúpula de un plutón.
\end{abstract}

Palabras claves: Plutón carbonífero, Xenolito kilométrico, 'Stoping', Deformación coaxial, Chile.

ABSTRACT

Interaction between the Pinchal Granodiorite and the Kilometric Xenolite of Cerro Negro, Sierra de Moreno, Antofagasta Region, Chile. The processes associated with the interaction between the Pinchal Granodiorite (PG) and the kilometric Cerro Negro Xenolith (KCNX) are studied. The PG was cooled during the Late 
Carboniferous, whereas the age of the KCNX remain until now unknown. The KCNX is immersed in the top of the PG. It is formed by a $600 \mathrm{~m}$ thick stratified succession of hornfels including sandstones, pelites and conglomerates. The sandstones are observed in the hornfels showing granoblastic fabric with recrystallized plagioclase, quartz, biotite, actinolite, hornblende and garnet. These minerals were formed at temperatures comprised between 320 and $550^{\circ} \mathrm{C}$. The $P G$ is mainly granodioritic and, in minor proportion, monzdioritic. In the western flank of the KCNX a porphyritic facies is present in the PG, whereas in its eastern contact the pluton mainly exhibits equigranular facies. In the western edge, the contact of the KCNX with the PG corresponds to a ductile shear zone. In the eastern edge, the contact is characterized by assimilation, presence of metasedimentary small xenoliths and injections of granitic material. In the latter, magmatic foliation and oblate enclaves are observed, whose deformation is related with the flow associated to the descendent movement of the KCNX. The KCNX display megascopic structures such as synclinal folding and deflection of layers in its northern part, which are interpreted as due to the gravitational fall of the KCNX in the magma of the PG by a stoping mechanism. The homoclinal attitude of the KCNX in its southern part, with increase of the dip of the layers between the western edge and the eastern edge, is interpreted as stretching that accompanied the tilting towards the southeast during its fall. Foliation and lineations within the KCNX represent ductile penetrative fabrics during this deformation. In addition ptigmatic veins, centimetric folds and boudinage are observed. Also structures of fragile-ductile character as tension gashes are present. On the basis of the analysis of strain in deformed conglomerates a coaxial deformation with a prolate ellipsoid developed. Tectonites are classified as $L S$. The history of the process of stoping of the KCNX is reconstructed, which started with its loosening of the country rock, metamorphism, deformation and, finally, collapse and halting within the mass of the PG. The present work demonstrates that magmatic stoping can occur on a great scale in the upper part of a pluton.

Key words: Carboniferous pluton, Kilometric xenolith, Stoping, Coaxial deformation, Chile.

\section{INTRODUCCIÓN}

La preservación de grandes bloques de roca de caja aislados en la cúpula de los plutones graníticos es relativamente rara, siendo los únicos bloques susceptibles de preservarse aquellos que quedan atrapados durante la última etapa de cristalización del magma (Paterson y Okaya, 1999), el cual, debido a su alta viscosidad, impide que los bloques se hundan rápidamente en la masa del plutón o sean asimilados por éste.

Aquí se presenta el caso de un gran xenolito de roca de caja denominado Xenolito kilométrico de Cerro Negro (XKCN), de edad aún desconocida, que quedó suspendido en el techo del plutón correspondiente a la Granodiorita Pinchal (GP), la cual se enfrió durante Carbonífero tardío (Fig. 1). Ambas unidades afloran en la Sierra de Moreno, $170 \mathrm{~km}$ al norte Calama (6855'39'39's/ $\left.22^{\circ} 27^{\prime} 11^{\prime \prime} \mathrm{W}\right)$. Su estudio revela el proceso de deformación a que fue sometido el XKCN, desde su deformación in situ, hasta su desprendimiento de la roca de caja, el consecuente metamorfismo y, finalmente, su hundimiento y detención dentro de la masa del plutón. Cabe señalar que la interacción entre la GP y el XKCN es mayormente física, no habiéndose observado fenómenos que indiquen reacciones químicas de importancia.

\section{GRANODIORITA PINCHAL}

La GP es un plutón de composición granodiorítica a monzogranítica con 14 km de largo en sentido noreste por $9 \mathrm{~km}$ de ancho en sentido noroeste, sin zonación composicional relacionada con su forma general.

\section{RELACIONES DE CONTACTO}

El contacto de la GP con su roca de caja es observable en su margen oeste donde, en forma subvertical, sinuosa, pero con rumbo general 

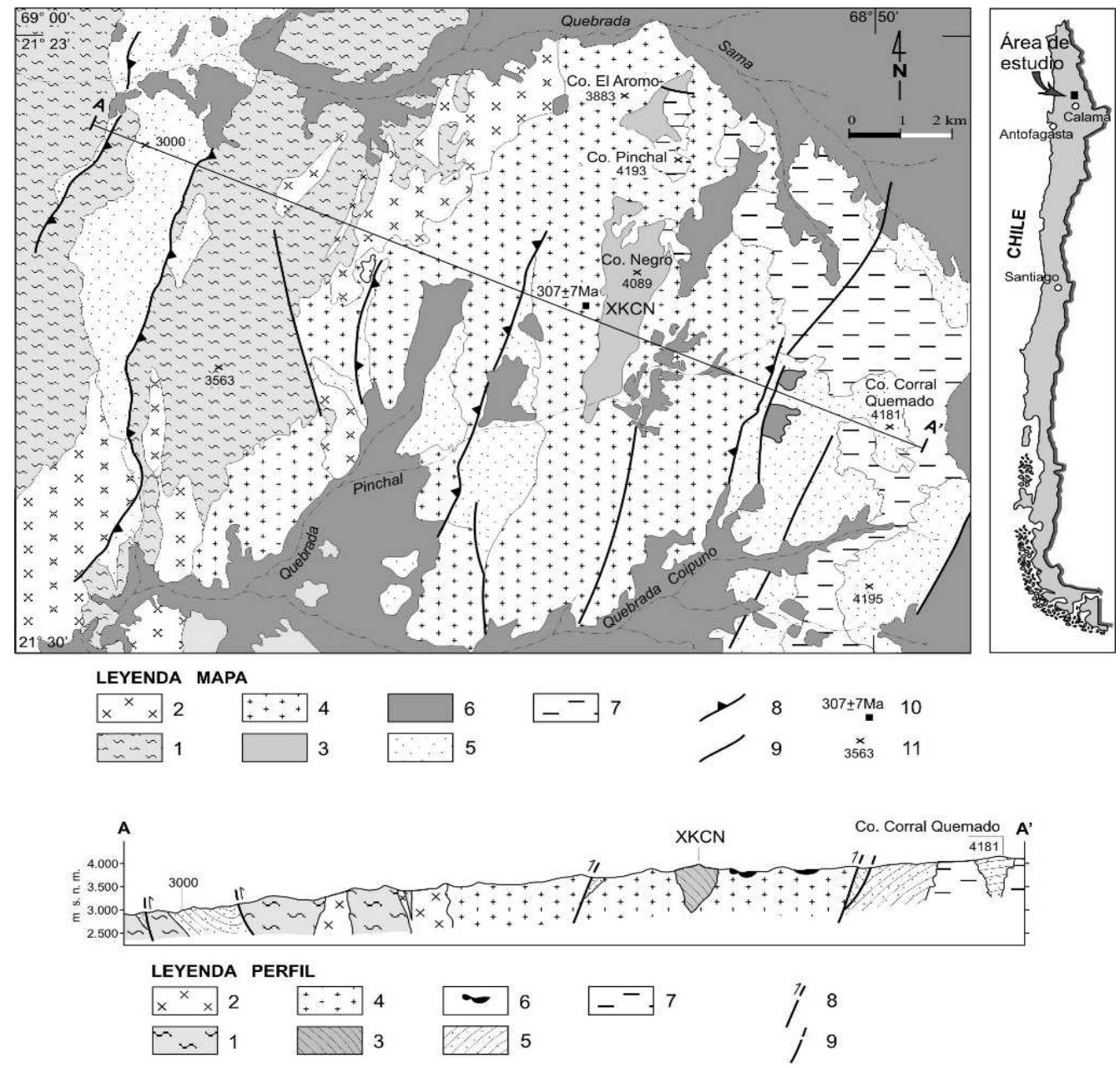

FIG. 1. Mapa geológico general y perfil estructural del área estudiada en la Sierra de Moreno, 170 km al norte de Calama, Región de Antofagasta. Según Niemeyer et al. (1985). Leyenda mapa 1- Basamento Metamórfico: esquistos micáceos, cuarcitas calcáreas, anfibolitas y migmatitas (Precámbrico); 2- dioritas de hornblenda y biotita (Paleozoico inferior?); 3- Xenolito kilométrico de Cerro Negro (XKCN), metasedimentitas: areniscas, pelitas y conglomerados (Carbonífero?); 4- Granodiorita Pinchal (GP): granodioritas a monzogranitos (Carbonífero inferior); 5- sedimentitas y volcanitas (Mesozoico); 6- volcanitas ácidas a intermedias (Terciario?). 7- monzodioritas (Terciario?); 8- fallas inversas, indicando bloque alzado; 9- fallas sin desplazamiento conocido. 10- edad K-Ar en biotita de la GP; 11- puntos de control altimétrico. Leyenda perfil 1- basamento metamórfico: esquistos micáceos, cuarcitas calcáreas, anfibolitas y migmatitas (Precámbrico); 2- dioritas de hornblenda y biotita (Paleozoico inferior?); 3- Xenolito kilométrico de Cerro Negro (XKCN) indicando estratificación, metasedimentitas: areniscas, pelitas y conglomerados (Carbonífero?); 4granodiorita Pinchal (GP): granodioritas a monzogranitos (Carbonífero inferior); 5-sedimentitas y volcanitas (Mesozoico) indicando estratificación; 6- volcanitas ácidas a intermedias (Terciario?); 7- monzodioritas (Terciario?); 8- fallas inversas, indicando movimiento del bloque colgante; 9 - fallas sin desplazamiento conocido.

noreste, intruye a rocas del Basamento Metamórfico de Sierra de Moreno. Dicho basamento, localmente denominado 'Complejo Metamórfico de Quebrada Sama' (Venegas y Niemeyer, 1982), está formado por esquistos micáceos, cuarcitas calcáreas, anfibolitas y migmatitas de probable edad precámbrica Niemeyer et al. (1985). En la figura 1 se muestra la distribución de la GP y su contacto con el mencionado Basamento.

También a lo largo de su borde occidental, la GP intruye a una diorita de hornblenda y biotita, en partes foliada, que forma cuerpos subconcordantes con la foliación general de rumbo noreste del mencionado Complejo, y que ha sido atribuida al 
Paleozoico inferior (Aguilar y Niemeyer, 1984). El material de la GP no presenta foliación magmática en el contacto con la roca de caja. Solamente se observan algunos apófisis graníticos de anchura métrica dentro de los 100-200 $\mathrm{m}$ de roca de caja próxima a dicho contacto.

Su borde oriental es un contacto por falla con rocas mesozoicas. Estas últimas cubren, a su vez, mediante no-conformidad, tanto al Basamento Metamórfico como a la GP. Asimismo, todas las unidades anteriores se presentan cubiertas por volcanitas ácidas a intermedias de posible edad terciaria, incluyendo ignimbritas distribuidas a lo largo de las principales quebradas del sector estudiado (Niemeyer et al., 1985).

En el medio de la GP aflora el XKCN como un gran bloque totalmente aislado (Fig. 1, perfil estructural A-A'). En el flanco occidental del XKCN, la GP presenta facies porfírica, la cual se extiende según una franja de sólo 300-400 m de ancho, en contacto con el XKCN. En el contacto con el borde oriental del $X K C N$, la GP presenta facies equigranular, que es, por lo demás, la facies predominante en el resto del plutón.

\section{FACIES PORFÍRICA OCCIDENTAL}

Corresponde a rocas de composición granodiorítica a monzogranítica con textura porfírica, en que los fenocristales alcanzan tamaños de 3 a 10 $\mathrm{mm}$, dentro de una masa fundamental de grano fino. Tienen un color rosado característico. Atravesándolas, suelen observarse diques aplíticos de ancho centimétrico, también de color rosado.

Esta facies está constituida por fenocristales de plagioclasa, feldespato potásico, cuarzo y minerales máficos. La plagioclasa es del tipo oligoclasa $\left(\mathrm{An}_{23}{ }^{-}\right.$ $\left.\mathrm{An}_{26}\right)$, con hábito tabular euhedral a subhedral, macla polisintética y zonación normal. El feldespato potásico corresponde a ortoclasa, presentando textura pertítica y también granofídica. El cuarzo se presenta en cristales subhedrales a anhedrales. Los minerales máficos están representados principalmente por biotita en cantidad igual o menor a $6 \%$, mientras que la hornblenda no supera el $1,5 \%$. Tanto la biotita como la hornblenda son subhedrales y se encuentran alteradas a clorita en los bordes y a lo largo de su clivaje (Nava, 2004). La masa fundamental está formada por entrecrecimiento anhedral de plagioclasa, microclina y cuarzo. También aparecen minerales opacos y minerales accesorios como circón y apatita.

\section{FACIES EQUIGRANULAR ORIENTAL}

Son rocas de composición granodiorítica y textura fanerítica hipidiomórfica equigranular con tamaño de grano 1,5-4,0 mm. Tienen un color gris claro. Están compuestas principalmente por plagioclasa de composición oligoclasa-andesina $\left(A n_{25}-A n_{34}\right)$, con hábito tabular euhedral a subhedral. Se observan como cristales con macla polisintética y zonación normal. El feldespato potásico corresponde a ortoclasa, que generalmente se presenta en cristales subhedrales a anhedrales. En ellos, suele observarse textura micropertítica y macla simple. El cuarzo es subhedral a anhedral y aparece rellenando espacios entre los demás minerales. Los minerales máficos se encuentran en una proporción inferior al 15\% y corresponden a hornblenda y biotita subhedral a anhedral, de los cuales algunos cristales se presentan parcialmente alterados a clorita. Se observan también cristales de mineral opaco, no determinado, en una proporción no inferior al 3\% y también aparecen circón y apatita en traza (Nava, 2004).

\section{EDAD}

Durante el presente estudio se obtuvo una edad $\mathrm{K}$-Ar en biotita de $307 \pm 7$ Ma (Tabla 1) en una muestra de la facies porfírica occidental de la GP, ca. $300 \mathrm{~m}$ al occidente del XKCN (Fig. 1). Se interpretó como una edad mínima, dado que se estima que la biotita perdió algo de su K por cloritización (C. Pérez de Arce, comunicación escrita, 2004). Dicha edad es concordante, dentro de los márgenes de error, con otra edad K-Ar de $297 \pm 10$ Ma en biotita obtenida por Huete et al. (1977) en el mismo plutón. Esta última fue posteriormente recalculada en $302 \pm 10$ Ma utilizando nuevas constantes de desintegración (A. Tomlinson, comunicación escrita, 2003). Ambas edades indican que el plutón se habría enfriado durante el Carbonífero Superior. 
TABLA 1. EDAD RADIOMÉTRICA DEL LA GRANODIORITA PINCHAL.

\begin{tabular}{|l|l|l|c|c|c|c|c|}
\hline $\begin{array}{l}\text { No. } \\
\text { Muestra }\end{array}$ & $\begin{array}{c}\text { No. } \\
\text { Laboratorio }\end{array}$ & Material & $\% \mathrm{~K}$ & $\begin{array}{c}\text { Ar rad } \\
\text { nl/g }\end{array}$ & $\begin{array}{c}\text { \%Ar } \\
\text { atm. }\end{array}$ & Edad Ma & $\begin{array}{c}\text { Error } \\
\mathbf{2 \sigma}\end{array}$ \\
\hline P42-MN-1102 & P268.P42 & $\begin{array}{l}\text { Biotita } \\
\text { cloritizada }\end{array}$ & 5,995 & 77,884 & 7 & 307 & \pm 7 \\
\hline
\end{tabular}

Datación realizada en el Laboratorio de Geocronología del Servicio Nacional de Geología y Minería, Santiago, Chile.

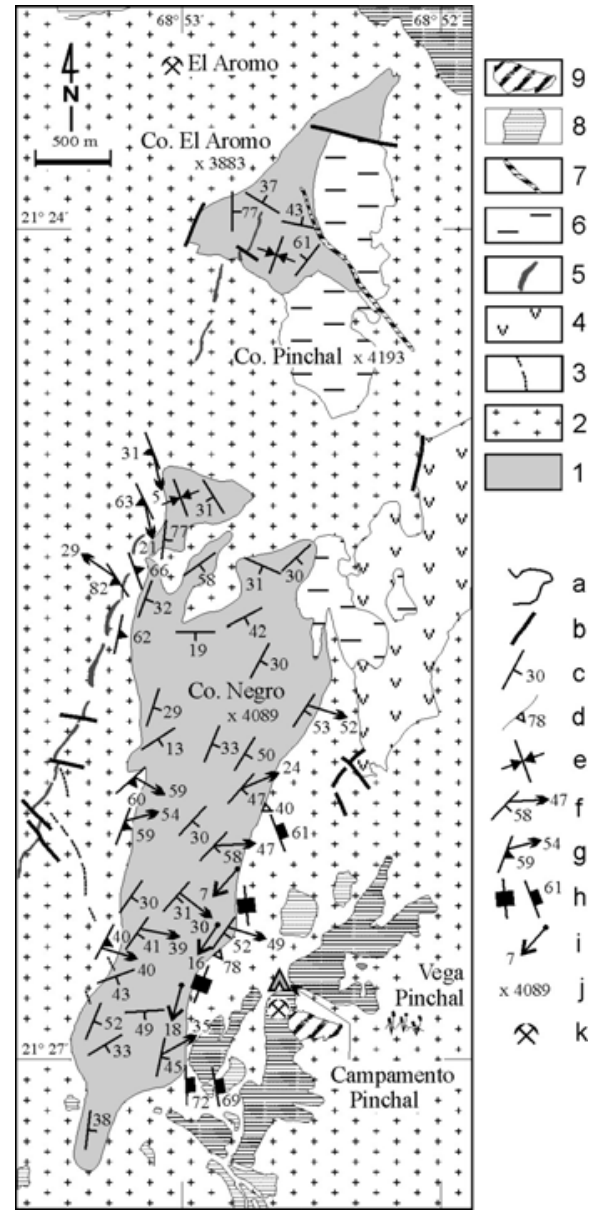

FIG. 2. Mapa geológico-estructural del Xenolito kilométrico de Cerro Negro y de sus alrededores; 1- Xenolito kilométrico de Cerro Negro (XKCN, Carbonífero?); 2- Granodiorita Pinchal (GP, Carbonífero Superior); 3- diques aplíticos (Carbonífero Superior); 4-volcanitas andesíticas y dacíticas (Terciario?); 5- diques riolíticos (Terciario?); 6monzodiorita (Terciario?); 7- veta de cuarzo y calcita; 8ignimbrita (Terciario Superior); 9- travertino (Terciario Superior). a- contacto litológico; b- falla; c- rumbo y manteo de estratificación; d- manteo del contacto; epliegue sinclinal; f- foliación metamórfica con lineación; $\mathbf{g}$ foliación milonítica con lineaci=ón; $\mathbf{h}$ - foliación magmática i-eje de pliegue centimétrico; j-cumbres; k-laboreo minero.

\section{XENOLITO KILOMÉTRICO DE CERRO NEGRO}

El XKCN alcanza una longitud de $7 \mathrm{~km}$ en sentido nor-noreste, con ancho variable de 200-1.400 m. Aflora segmentado en dos cuerpos: uno septentrional y otro meridional. El segundo es mucho más extenso que el primero. El cuerpo meridional se encuentra totalmente rodeado por rocas de la GP, incluso en su parte superior, lo que indica que, al menos este cuerpo es un xenolito. Obliterando el contacto oriental de ambos cuerpos se observa un plutón monzodiorítico posiblemente terciario (Fig. 2).

Se sugiere su correlación con una secuencia de pelitas y areniscas que, dispuesta en discordancia angular sobre las rocas del Basamento Metamórfico de Sierra de Moreno, ha sido reportada por Breitkreuz (1986) en Quebrada Arcas, $50 \mathrm{~km}$ al suroeste del área aquí estudiada. Dicho autor atribuyó al Carbonífero sensu lato ese afloramiento. Sin embargo, hasta el momento no se dispone de antecedente alguno que permita una asignación cronológica certera ni a la secuencia de Quebrada Arcas ni a la del XKCN.

El XKCN está constituido por una secuencia de rocas metasedimentarias, de $600 \mathrm{~m}$ de espesor, procedente principalmente de areniscas con delgadas y escasas intercalaciones milimétricas de pelitas, además de algunas capas métricas de conglomerados. Los protolitos de las metaareniscas son arcosas de grano fino a muy fino. Las metaareniscas son de color verde a pardo oscuro. Este último color se debe al teñido de material ferruginoso. Presentan, por lo general, buena estratificación planar en capas de 20 a $30 \mathrm{~cm}$ de espesor, en parte laminadas, sin gradación en el tamaño del grano de base a techo. Los conglomerados contienen clastos bien redondeados de hasta $2,0 \mathrm{~cm}$ de diámetro, compuestos de cuarzo policristalino y de agregados cuarzo-feldespáticos, posiblemente deri- 
vados de riolitas. Éstos se encuentran sostenidos por la matriz. La presencia de estratificación cruzada y de estratificación ondulada relictas en las metaareniscas indica una posición normal para la secuencia (Nava, 2004). Las metaareniscas del $\mathrm{XKCN}$ son totalmente diferentes a las cuarcitas del Basamento metamórfico de Sierra de Moreno, las cuales corresponden a cuarcitas con importantes contenidos de carbonato cálcico en su matriz. Efectivamente, estas últimas son de color gris blanquecino en las cuales el material ferruginoso se encuentra totalmente ausente, no tienen estratificación cruzada y carecen de intercalaciones conglomerádicas (Griem-Klee y Niemeyer, 2005).

\section{METAMORFISMO EN EL XKCN}

Las areniscas del XKCN son corneanas que al microscopio se manifiestan por el desarrollo de una matriz de fábrica granoblástica con minerales neoformados de cuarzo, plagioclasa, biotita, actinolita, hornblenda y granate de tamaño 0,05 $0,5 \mathrm{~mm}$, dejando aislados granos detríticos originales de feldespato y cuarzo de tamaño 0,5$0,8 \mathrm{~mm}$. Es común observar bordes parcialmente recristalizados en estos últimos. El cuarzo de la matriz tiene un aspecto limpio con desarrollo de granos de bordes rectos y puntos triples o textura del tipo 'foam structure' (Passchier y Trouw, 1996). En la figura 3, de la presente contribución, se ilustra este tipo de textura para las metaareniscas del XKCN.

El grado de metamorfismo del XKCN está dado por la formación de tres asociaciones mineralógicas. La primera asociación corresponde a la paragénesis actinolita-biotita-cuarzo-plagioclasa, propia de la facies corneana de albita-epidota, formada en condiciones de temperaturas de 320 a $450^{\circ} \mathrm{C}$ (Yardley et al., 1990). Las dos restantes, constituidas por hornblenda-granate y biotita-actinolitahorblenda, son características de la facies corneana de horblenda, estables en el rango $450-600^{\circ} \mathrm{C}$ (Yardley et al., 1990; Best, 2003).

El reemplazo de clorita por granate y la persistencia de biotita permiten acotar la temperatura máxima que alcanzó el metamorfismo en el intervalo $500-550^{\circ} \mathrm{C}$ (Bucher y Frey, 2002). El avanzado grado de recristalización que presentan estas rocas, así como el desarrollo de fábricas granoblásticas, la recristalización en los bordes de granos relictos de feldespato, la existencia de cuarzo por nucleación y el crecimiento de nuevos granos, son consistentes con las temperaturas propuestas a partir de las paragénesis metamórficas.

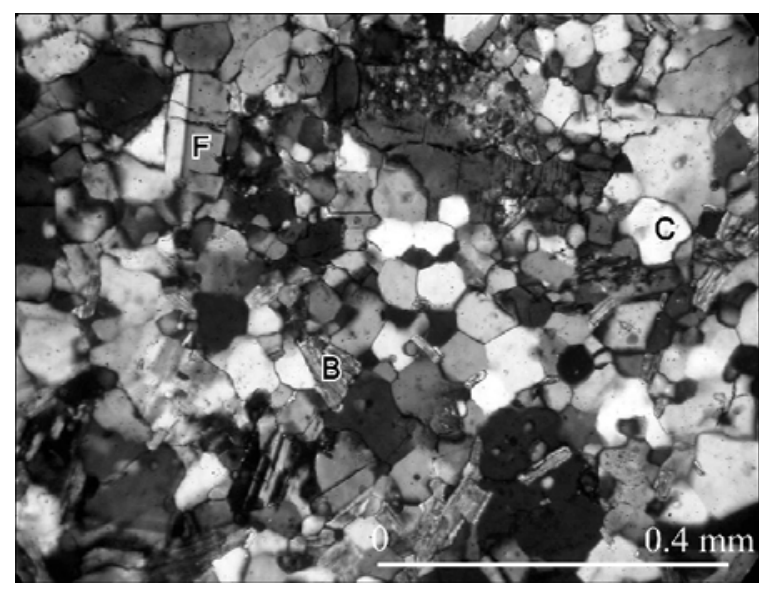

FIG. 3. Textura de recristalización del tipo 'foam structure' en metaareniscas del XKCN, caracterizada por numerosos puntos triples desarrollados entre cristales de cuarzo y feldespato; C- cuarzo; F- feldespato; B- biotita. Fotografía a nícoles cruzados. 


\section{RELACIONES DE CONTACTO DEL XKCN}

Las relaciones de contacto entre el XKCN y la GP se manifiestan de distinta manera en su borde occidental que en su borde oriental. En el borde occidental el contacto corresponde a una zona de cizalle dúctil desarrollada en la facies porfírica de la GP. En el borde oriental, en cambio, el contacto se caracteriza por asimilación de la roca del XKCN y presencia de xenolitos de metasedimentitas dentro de la facies equigranular de granodiorita, además de inyecciones de material de la GP.

\section{CONTACTO OCCIDENTAL}

A lo largo de este contacto se observan bandas de cizalle dúctil de 0,1 a 3,0 m de ancho que, afectando a la facies porfírica occidental de la GP, conforman franjas de rocas miloníticas. En su parte norte, las bandas de cizalle están en contacto con las rocas del $\mathrm{XKCN}$, donde presentan rumbos $\mathrm{N} 15^{\circ} \mathrm{W}$ a $\mathrm{N} 26^{\circ} \mathrm{W}$ con manteos de 32 a $63^{\circ}$ al suroeste. En la parte sur las bandas de cizalle se alejan hacia el oeste del contacto, hasta una distancia de 20 a 30 $\mathrm{m}$, donde tienen rumbos $\mathrm{N} 14^{\circ} \mathrm{E}$ hasta $\mathrm{N} 47^{\circ} \mathrm{E}$ y manteos de 40 a $62^{\circ}$ al sureste. Estas bandas contienen una lineación de estiramiento con buzamiento de $24-40^{\circ} \mathrm{SE}$ y de $54^{\circ} \mathrm{NE}$ (Fig. 2). Su sentido de movimiento está marcado por la inflexión sigmoidal de la foliación milonítica que indica el descenso del bloque oriental respecto del bloque occidental (Fig. 4a). La magnitud del desplazamiento a lo largo de una zona de cizalle no homogéneo queda determinada por la ecuación:

$$
D=\int_{0}^{z} \gamma d z
$$

en la que $D$ corresponde al desplazamiento total, que puede calcularse empíricamente como el área bajo la curva en un gráfico z (distancia perpendicular a la zona de cizalle) versus $\gamma$ que es el valor del cizalle en cada punto de la zona de cizalle (Ramsay y Graham, 1970). Se llega a un valor de $D=33 \mathrm{~cm}$ para una banda de cizalle de 15 $\mathrm{cm}$ de ancho, con un valor $=14$ en la parte central de la banda, que se ha tomado como ejemplo (Fig. 4b). Una extrapolación muy aproximada de este
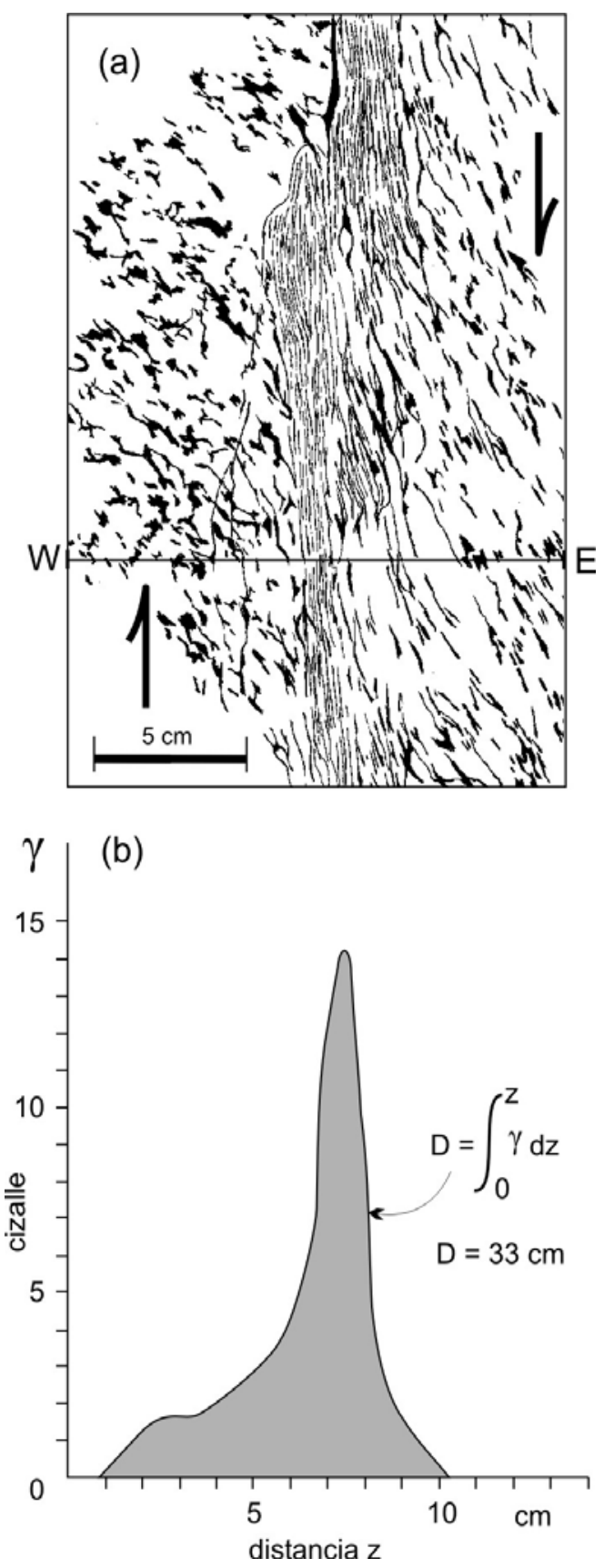

FIG. 4. Ejemplo de banda de cizalle dúctil observada en el borde occidental de la GP; (a)- deflexión de la foliación milonítica indicando descenso del bloque oriental respecto del bloque occidental. E-W indica el perfil este-oeste según el cual se determinó el desplazamiento; (b)- gráfico de distancia z versus valor del cizalle $\gamma$. El área bajo la curva indica el valor del desplazamiento. 
valor a una banda de cizalle de $3 \mathrm{~m}$ de ancho sugiere un desplazamiento máximo del orden de los $6 \mathrm{~m}$.

Además se han observado estructuras $S-C$, según definición de Berthé et al. (1979), así como también microestructuras de tipo 'mica-fish' (Simpson y Schmid, 1983; Passchier y Trouw, 1996), las cuales constituyen indicadores cinemáticos útiles y consistentes con la determinación del sentido de cizalle arriba establecido.

Se ha sugerido que, durante la última fase de cristalización de un magma, la migración de los bordes de granos provocaría un debilitamiento termal dentro del material en proceso de enfriamiento (Gapais y Barbarin, 1986), contrario a lo que pudiera esperarse durante su solidificación (Van der Molen y Paterson, 1979). Por lo tanto, es posible explicar por este mecanismo la presencia de bandas de cizalle en la vecindad del contacto entre el XKCN y la GP.

Posteriormente, una vez enfriada la roca por debajo de los $320^{\circ} \mathrm{C}$ de temperatura, el cizalle continuó en condiciones frágiles, generando cataclasitas sobreimpuestas sobre las mismas bandas de cizalle miloníticas.

\section{CONTACTO ORIENTAL}

En el contacto oriental se observan evidencias de una marcada invasión del magma hacia el XKCN en un ancho de $30 \mathrm{~m}$. Efectivamente, se observan allí apófisis de material ígneo que intruyen tanto paralela como transversalmente a la foliación, produciendo xenolitos métricos a centimétricos de

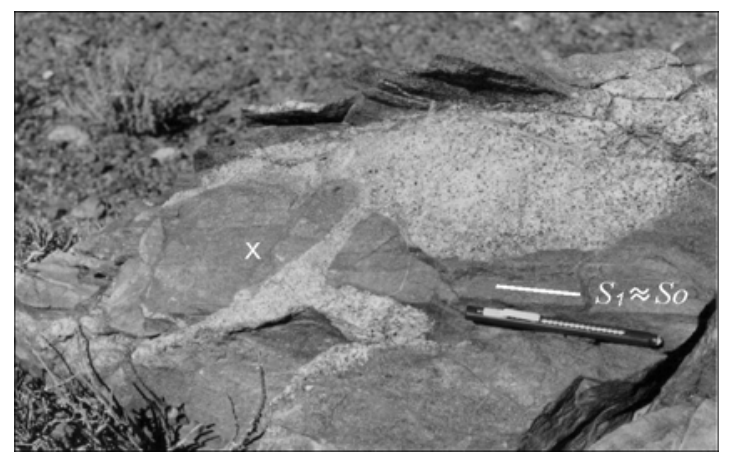

FIG. 5. Apófisis de la GP dentro del XKCN en su contacto oriental. Aislamiento de un xenolito centimétrico $(X)$ de la metaarenisca del XKCN dentro del material magmático de la GP. Se indica la foliación subparalela a la estratificación ( ). contornos muy angulosos (Fig. 5).

Las intrusiones de magma paralelas a la foliación llegaron a formar venas de inyección de grano muy fino, aplíticas, con anchos de 0,3 a $1,5 \mathrm{~cm}$ y espaciamiento de 2,4 a 4,4 cm (Fig. 6). Debido a que las venas se restringen a la proximidad inmediata del contacto con la GP, ellas se interpretan como provenientes directamente de la GP.

Los contactos angulosos perpendiculares a la estratificación se interpretan como la intrusión de magma granítico a lo largo de fisuras frágiles de la roca de caja (Thorpe y Brown, 1985) y las inyecciones paralelas al plano de estratificación habrían sido facilitadas por la laminación en las areniscas y por el fuerte manteo de 45 a $58^{\circ} \mathrm{SE}$ que alcanzan las capas del XKCN en su borde oriental.

\section{FOLIACIÓN MAGMÁTICA Y ENCLAVES ELONGADOS}

Cerca del borde suroriental del XKCN, se ha identificado una foliación magmática débilmente

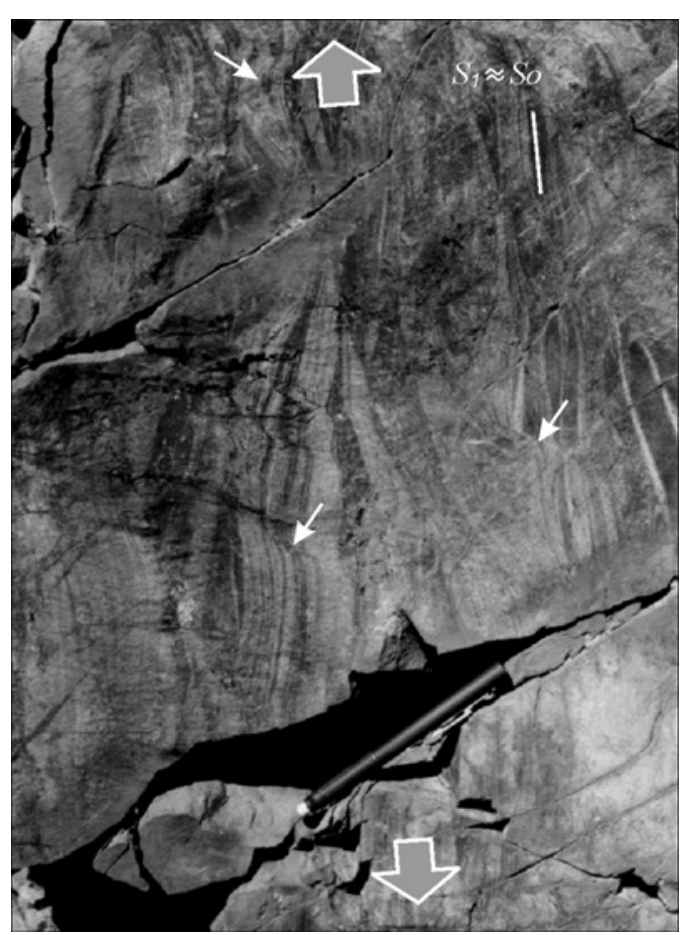

$S_{1} \approx S_{0}$

FIG. 6. Inyecciones de venas aplíticas paralelas a a foliación en el borde oriental del XKCN. Bandas de cizalle extensionales oblicuas conjugadas, indicadas por flechas delgadas, desplazan el conjunto de foliación, más las venas aplíticas. Las flechas gruesas indican dirección y sentido de máxima extensión. 
desarrollada con rumbo subparalelo a dicho borde y manteos variables entre $61-72^{\circ} \mathrm{NE}$ y $90^{\circ}$. Al microscopio, la foliación está dada por la orientación paralela de cristales subhedrales de plagioclasa, hornblenda y biotita, entre los cuales se observan agregados, no alineados, de ortoclasa, además de cuarzo, ambos intersticiales y anhedrales. Dicha disposición proporciona una textura hipidiomórfica inequigranular orientada, típicamente magmática (Paterson et al., 1989).

También es posible reconocer abundantes enclaves de composición diorítica, con tamaños de 2-20 cm. La forma de los enclaves es elipsoidal aplastada y se disponen con rumbos variables entre $\mathrm{N} 20^{\circ} \mathrm{W}$ y N20${ }^{\circ} \mathrm{E}$ con manteos de 61 a $72^{\circ} \mathrm{NE}$ a subverticales. Sus ejes mayor e intermedio se orientan de manera subparalela a la foliación magmática, la que a su vez es subparalela a la traza del contacto oriental del XKCN. A través de la medida de los ejes de las formas elipsoidales de los enclaves se ha podido reconstruir las correspondientes elipses de deformación mediante el método de Lisle (1977), suponiendo que la forma original de los enclaves fue esférica. Se llega a la conclusión que se trata de elipsoides oblados, como puede observarse en secciones horizontales y en secciones verticales (ver Fig. 13).

La foliación magmática marca, en este caso, la trayectoria del flujo magmático imperante durante la intrusión de un plutón (Marre, 1982). La orientación de la foliación, aunque débil y limitada al borde suroriental con el XKCN, así como también las formas obladas de los enclaves, se asocian con el flujo del magma de la GP en torno al XKCN.

\section{ESTRUCTURAS MEGASCÓPICAS EN EL XKCN}

El cuerpo septentrional del XKCN forma un sinclinal hectométrico, abierto, de eje subhorizontal con rumbo nornoreste. El cuerpo meridional, en cambio, se caracteriza por presentar una actitud homoclinal de las capas, que varían en manteo desde $24^{\circ} \mathrm{SE}$ en el borde occidental hasta $69^{\circ} \mathrm{SE}$ en el borde oriental. Su borde norte presenta manteos variables de $21^{\circ} \mathrm{S}$ a $58^{\circ} \mathrm{SE}$, marcando una fuerte deflexión de las capas respecto a la parte sur del cuerpo. Además, se ha mapeado en ese lugar un sinclinal hectométrico, de eje subhorizontal con rumbo nornoroeste (Fig. 2).

\section{ESTRUCTURAS MESOSCÓPICAS EN EL XKCN}

Dentro del XKCN existen estructuras mesoscópicas que se expresan por el desarrollo de fábricas penetrativas dúctiles tales como foliación y lineaciones metamórficas. Además se observan venas ptigmáticas, pliegues y 'boudinage'. También afloran estructuras de carácter frágil-dúctil como grietas de tensión.

\section{FOLIACIÓN METAMÓRFICA}

Se ha observado una foliación $S_{1}$ moderadamente penetrativa y paralela al plano de estratificación $S_{0}$. Ella se encuentra especialmente marcada en intercalaciones pelíticas cercanas al contacto oriental del XKCN, donde su aspecto esquistoso es más evidente. A escala microscópica se manifiesta por una disposición paralela del plano (001) de la biotita, observándose realzada por concentraciones del mencionado mineral en bandas con espesor de 0,3 a 0,8 mm, y espaciamiento promedio de 2,0 mm. La textura de esas bandas es lepidoblástica en tanto que la textura entre bandas es grano-lepidoblástica (Nava, 2004).

\section{LINEACIONES}

Las rocas del XKCN muestran un buen desarrollo de dos tipos de lineaciones. El primero corresponde a una lineación que se expresa macroscópicamente en metaareniscas como surcos de $1 \mathrm{~cm}$ de ancho por 8-10 cm de largo contenidos en la superficie de foliación (Fig. 7). Su ancho es milimétrico en las intercalaciones de pelitas. El valor del buzamiento de la lineación aumenta desde $30^{\circ}$ en el noroeste hasta $49^{\circ}$ en el sureste, conjuntamente con el incremento del valor del manteo de la estratificación 
en el cuerpo principal del XKCN. Al microscopio, corresponde a una lineación por arreglo paralelo de granos ('grain lineation'; Piazolo y Passchier, 2002). Está dada por un alineamiento paralelo muy conspicuo de actinolita observable, en una sección estructural perpendicular a la foliación y paralela a la lineación macroscópica. La actinolita forma textura nematoblástica en que sus cristales se disponen paralelamente a la lineación macroscópica. Además se observa una orientación dimensional de los granos de feldespato y cuarzo, paralela a la orientación de la actinolita (Fig. 8).

El segundo tipo de lineación queda definido por clastos elongados en conglomerados, dentro de los cuales la dirección de elongación de los clastos yace sobre el plano de foliación. A escala microscópica, los clastos de los conglomerados se encuentran internamente formados por agregados granoblásticos de cuarzo en que los granos individuales presentan una elongación menos marcada que el conjunto. Corresponde a una lineación del tipo de agregado ('aggregate lineation'; Piazoloy Passchier, 2002). Esta lineación es paralela a la lineación de cristales de actinolita observada en metaareniscas. Ambas se interpretan como lineaciones de estiramiento por ser perpendiculares a los cuellos de 'boudins' y a las grietas de tensión.

\section{BANDAS DE CIZALLE}

El conjunto de foliación más las inyecciones aplíticas aparece desplazado por bandas de cizalle conjugadas simétricamente oblicuas que, formando ángulos de ca. $45^{\circ}$ con la foliación (Fig. 6), producen

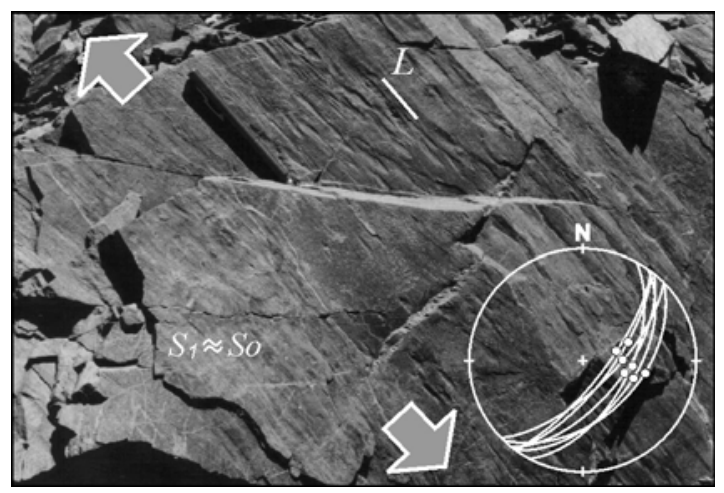

FIG. 7. Lineación macroscópica, $L$ contenida en el plano de foliación. En elángulo inferior derecho se muestran medidas de planos de foliación conteniendo la lineación (círculos blancos, n=7). Red de Schmidt, hemisferio inferior. Sector suroriental del XKCN. las flechas indican la dirección y sentido.

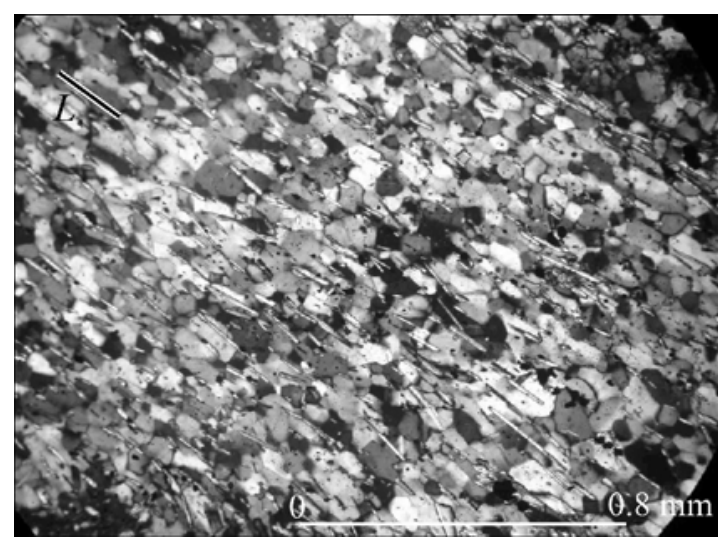

FIG. 8. Textura nematoblástica en que los cristales de actinolita se disponen paralelamente a la lineación macroscópica. Fotografía a nícoles cruzados.

desplazamientos dúctiles del orden de 2 a $5 \mathrm{~cm}$. Las bandas de cizalle se interpretan como producto de la extensión coaxial que sufrió el material en forma paralela a la foliación, según lo establecido por Platt y Vissers (1980). El hecho de que las bandas de cizalle oblicuas aparezcan inyectadas por aplitas indica que su formación es previa o simultánea a la cristalización del magma de la GP.

\section{VENAS PTIGMÁTICAS}

A lo ancho del cuerpo principal del XKCN se ha reconocido una serie de venas ptigmáticas de composición tonalítica y textura de grano fino que, con espesor de 2 a $6 \mathrm{~mm}$, conforman pliegues concéntricos de longitud de onda centimétrica (Fig. 9). Cortan en diferentes ángulos a la estratificación original de las metasedimentitas.

Las venas ptigmáticas son de gran utilidad en la medición del valor del acortamiento producido durante la deformación de una roca (Ramsay, 1967). Se utilizó este tipo de venas con orientación perpendicular al plano de foliación para cuantificar el parámetro de extensión ocurrido en esa dirección. Se obtuvieron valores de $e_{3}$ comprendidos entre 0,22 y -0,43, lo cual significa que ocurrió un acortamiento de 22 a 43\%. El valor máximo, 43\%, está de acuerdo con el valor máximo determinado por el método de Fry (1979) en conglomerados que fueron afectados por acortamiento perpendicular al plano de foliación (Tabla 2). Por este motivo, ese valor se interpreta como el máximo acortamiento ocurrido durante la deformación del XKCN. El valor mínimo 


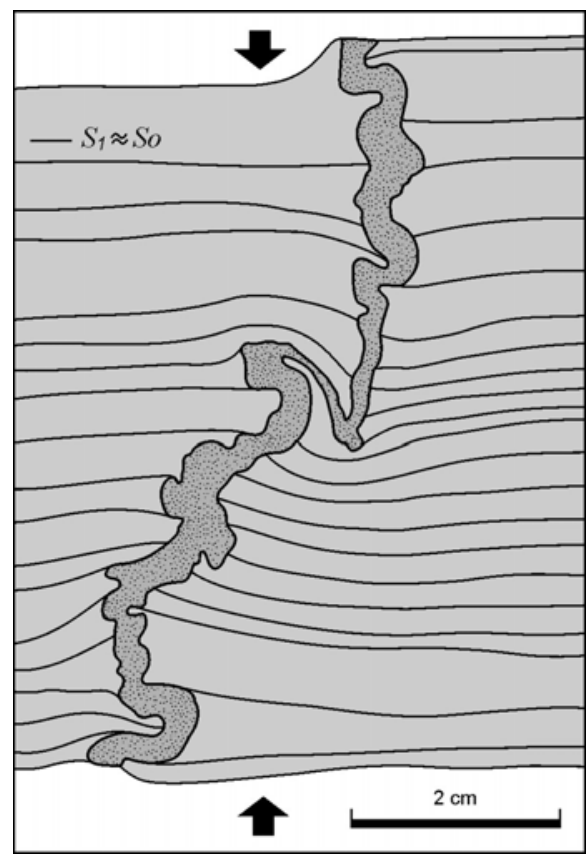

FIG. 9. Vena ptigmática perpendicular a la foliación, plegada según un acortamiento calculado de $43 \%$. Las flechas indican la dirección y sentido de máximo acortamiento.

de $22 \%$ de acortamiento es algo menor al obtenido en clastos de conglomerados y se interpreta como el mínimo acortamiento perpendicular a la estratificación ocurrido dentro del XKCN.

\section{'BOUDINS'}

Las estructuras del tipo 'boudins', se deben a la

TABLA 2. VALORES DEEJES PRINCIPALES DE DEFORMACIÓN PARA TRES MUESTRAS DE CONGLOMERADOS.

\begin{tabular}{|l|c|c|}
\hline $\boldsymbol{X}$ & $\boldsymbol{Y}$ & $\boldsymbol{R}_{X Y}$ \\
1 & 0,57 & 1,75 \\
1 & 0,43 & 2,33 \\
1 & 0,50 & 2,01 \\
\hline \multicolumn{3}{|c|}{$\boldsymbol{R}_{X Y}$ promedio } \\
\hline $\boldsymbol{Y}$ & $\boldsymbol{Z}$ & $\mathbf{2 , 0 0}$ \\
0,57 & 0,36 & $\boldsymbol{R}_{Y Z}$ \\
0,43 & 0,31 & 1,58 \\
0,50 & 0,43 & 1,39 \\
\hline \multicolumn{3}{|c|}{$\boldsymbol{R}_{Y Z}$ promedio } \\
\hline \multicolumn{2}{|c|}{$\mathbf{1 , 3 5}$} \\
\hline
\end{tabular}

deformación de materiales más competentes encajados dentro de una matriz incompetente, de menor viscosidad relativa, que es susceptible de deformarse de manera dúctil (Ramsay, 1982). En el XKCN, los 'boudins' presentan inyecciones de venas félsicas paralelas a la foliación, las cuales han sido estranguladas por extensión, conformando una serie de 'boudins' centimétricos, en que la estratificación se deflecta en torno a ese material.

Es posible distinguir dos tipos de 'boudins'. Un primer tipo de 'boudin', observado en la mitad occidental del XKCN, corresponde a estructuras del tipo 'tableta de chocolate' de sólo 3 a $4 \mathrm{~cm}$ de ancho. En este caso, las venas félsicas, exclusivamente formadas por cuarzo, se observan segmentadas en dos direcciones paralelas a la foliación. El origen de estas estructuras sería producto de un acortamiento homogéneo perpendicular a la foliación.

Un segundo tipo ocurre sólo en el flanco suroccidental del XKCN y consiste en 'boudins' de aspecto 'pinch-and-swell' (Ramsay, 1967) de $20 \mathrm{~cm}$ de alto por anchos de 4 a $5 \mathrm{~cm}$, con ejes subhorizontales de hasta $50 \mathrm{~cm}$ de longitud. Los cuerpos de los 'boudins' suelen observarse completamente segmentados, en cuyo caso los cuellos aparecen inyectados por material pegmatítico. La orientación de los cuellos de los 'boudins' guarda una relación de perpendicularidad con la lineación. Este hecho es un argumento en favor de que se trata de una lineación de estiramiento. De este modo, ella marca la dirección de máxima extensión (Fig. 10).

Ambos tipos de estructuras reflejan campos de deformación diferentes, lo que implica distintas etapas en la evolución estructural del XKCN, o bien que el primer tipo de 'boudin' represente heterogeneidades locales de la deformación, puesto que se le ha observado en un solo lugar.

\section{GRIETAS DE TENSIÓN}

Cerca del borde oriental del XKCN, existen grietas de tensión de 2 a $30 \mathrm{~cm}$ de largo por 0,5 a $4 \mathrm{~cm}$ de ancho, rellenas con material pegmatítico. El plano de las grietas de tensión es subperpendicular al plano de foliación. Por otra parte, se constata que los polos de esos planos se distribuyen, en red de Schmidt, dentro de la misma área que la lineación de estiramiento (Fig. 11). Lo anterior señala que los planos de las grietas de tensión son perpendiculares a la lineación y, por ende, éste es un argumento 


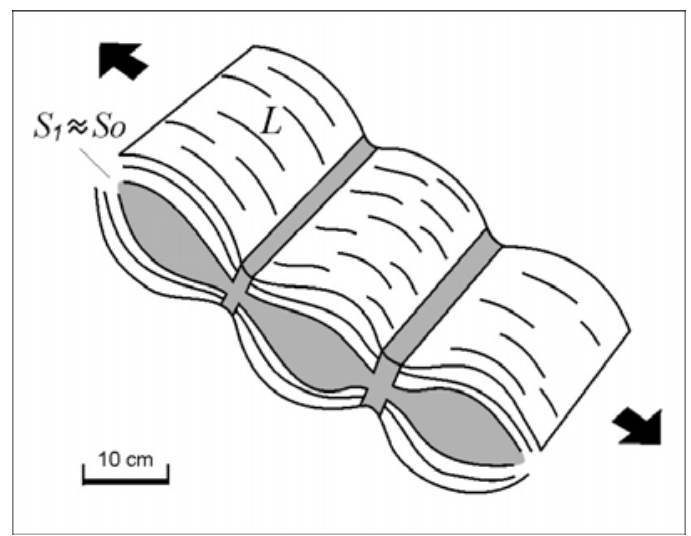

FIG. 10. Estructura de' boudins' de tipo 'pinch-and-swell' con relleno de los cuellos y de la parte central de la estructura por material plutónico pegmatítico. La lineación $L$ es perpendicular a los cuellos. Las flechas indican la dirección y sentido de máxima extensión.

más en favor de que se trata de una lineación de estiramiento.

\section{PLIEGUES}

En afloramientos del borde suroriental del XKCN se observan pliegues simétricos de escala métrica a centimétrica que, con ángulo interlimbo cerrado del orden de 30 a $40^{\circ}$, buzan 7 a $18^{\circ}$ al suroeste (Fig. 2). Se encuentra plegando al plano de foliación y a la lineación contenida en dicho plano (Fig. 12). Esto indica que el plegamiento es posterior a la formación de la foliación y de su lineación de estiramiento.

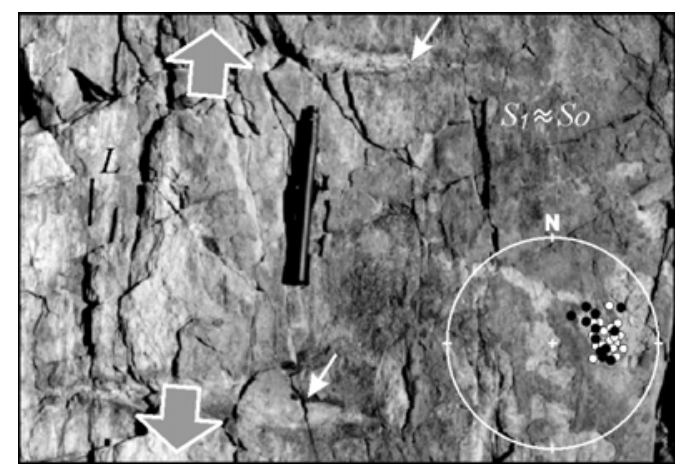

FIG. 11. Grietas de tensión rellenas con material pegmatítico, indicadas por flechas delgadas. Se marca la dirección de la lineación $L$. En el ángulo inferior derecho se muestran medidas de lineación (círculos blancos, $n=18$ ) y polos de grietas de tensión (círculos negros, $n=12$ ). Red de Schmidt, hemisferio inferior. Las flechas gruesas indican la dirección y sentido de máxima extensión.

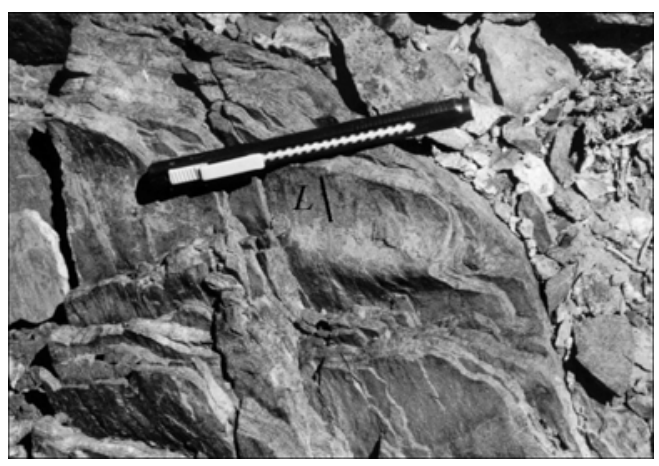

FIG. 12. Pliegue centimétrico afectando a la foliación y a la lineación $L$ contenida en la primera.

\section{ANÁLISIS DE LA DEFORMACIÓN EN CONGLOMERADOS}

Para el análisis de la deformación en conglomerados se utilizó el método de Fry (1979), según el cual se determina la orientación y magnitud de la elipse de deformación en un plano determinado. Se usó el programa computacional 'GeoFryPlot' (Holcome, 1999*), que aplica de forma automatizada dicho método.

Se determinó la magnitud y orientación de los ejes principales del elipsoide de deformación $X, Y$, $Z$ en tres muestras, convenientemente orientadas, de conglomerados deformados procedentes de diferentes partes del XKCN. En cada muestra, se utilizaron tres secciones perpendiculares entre sí: una sección perpendicular a la foliación y paralela a la lineación, otra paralela a la foliación y a la lineación, y una última perpendicular a la foliación y a la lineación. Los valores de cada uno de los ejes de dicho elipsoide se indican, para cada una de las muestras, en la tabla 2.

Se recurrió al gráfico de Flinn (Ramsay y Huber,

\footnotetext{
*Holcome, R.J. 1999. Strain calculator, GhoshFlow: Programs to calculate and model strain, shear, and vorticy parameters: http:// www.earthsciences.uq.edu.au/ rodh/publications/SGTSG StrainCalc.
} 


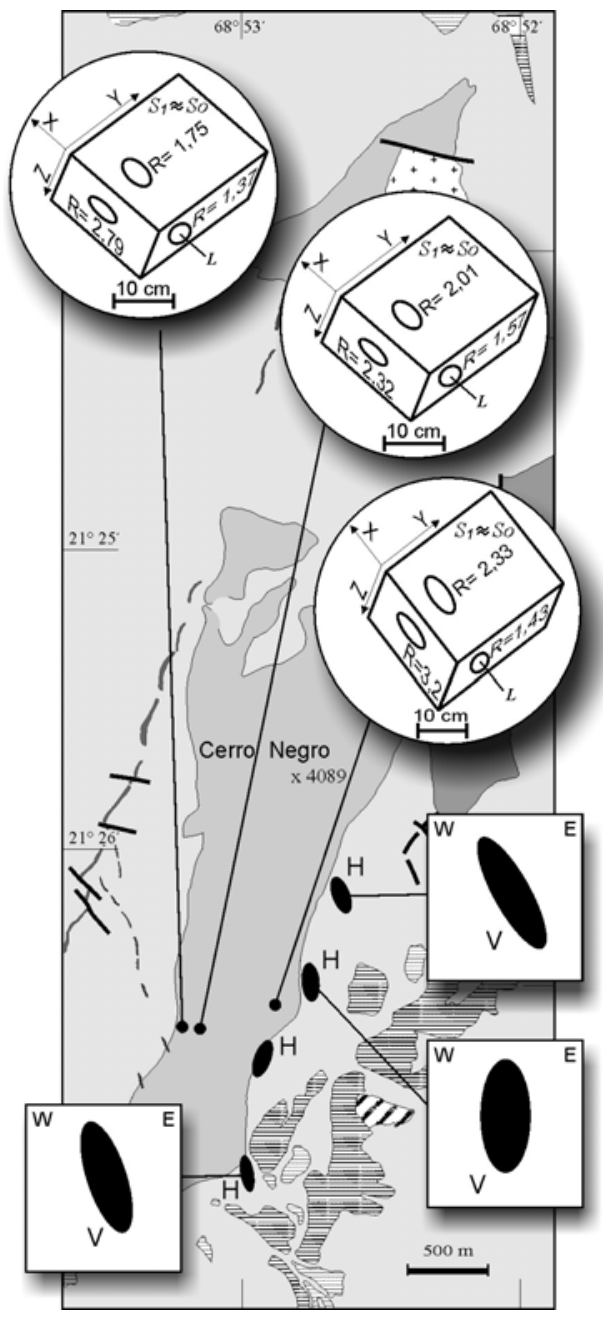

1983) con el fin de clasificar el elipsoide de deformación. Usando el promedio de $R_{X Y}$ y $R_{Y Z}$ señalado en la tabla 2 se llegó a un valor $k=R_{X Y}-1=2,82$. Éste cae en el campo de la constricción aparente con forma prolada del elipsoide, pudiendo clasificarse como una tectonita $L S$. El eje de máxima elongación $X$ presenta una orientación promedio $\mathrm{N} 70^{\circ} \mathrm{W}$ con buzamiento de $13^{\circ}$ al sureste en el borde occidental del XKCN, y buzamiento de $49^{\circ}$ al sureste en su sector oriental. Tiene una orientación paralela a la lineación mineral definida por la actinolita. El eje menor del elipsoide, $Z$, se orienta perpendicularmente a la foliación, con valores variables en el rango 0,36-0,43 (Tabla 2). El eje $Y$, con valores comprendidos en el rango 0,43-0,57 yace en el plano de la foliación (Fig. 13).

Según lo anteriormente expuesto, se comprueba que la deformación se produjo por un estiramiento máximo según la lineación dominante observada en el XKCN. El acortamiento máximo sucedió perpendicularmente al plano de foliación.

\section{INTERPRETACIÓN Y CONCLUSIONES}

Tanto los pliegues sinclinales hectométricos como la deflexión de capas en la parte septentrional del cuerpo principal del XKCN se interpretan como directamente relacionados con la caída gravitacional, por desprendimiento de éste dentro del magma de la GP, durante un proceso de 'stoping' ocurrido en su cúpula. En cambio, la actitud homoclinal del XKCN en su parte meridional, con aumento progresivo de manteo de las capas desde el borde occidental hacia el borde oriental, se interpreta como producto de extensión, debido al basculamiento hacia el sureste durante su caída dentro del magma (Fig. 14). La ausencia de paralelismo de los ejes de pliegues, sugiere que ellos se formaron durante la interacción entre el material del XKCN y la masa fluida viscosa de la GP, más que por un plegamiento tectónico anterior o simultáneo al emplazamiento de la GP.

Con el caso de estudio abordado en la presente contribución se demuestra que el 'stoping' magmático puede darse a gran escala en la cúpula de un plutón. El análisis de las estructuras mesoscópicas del XKCN revela el proceso de 'stoping', desde su desprendimiento de la roca de caja, deformación, hundimiento y detención dentro de la masa del plutón. La deformación actuó conjuntamente con el calentamiento del XKCN, causando una recristalización intensa, en condiciones metamórficas 
comprendidas de temperatura dentro del rango $320-550^{\circ} \mathrm{C}$.

En una etapa temprana, previa al desprendimiento del XKCN de la roca de caja, el magma penetró en las fisuras de la roca de caja, aislando el xenolito. Se originó una fábrica de aplastamiento por cizalle puro evidenciada por la foliación, en conjunto con el plegamiento de las venas ptigmáticas. La foliación, tanto en el xenolito como en la roca de caja, se debería a la fuerte compresión ejercida por el magma hacia arriba, perpendicularmente a la estratificación, en la cúpula de la GP (Fig. 14a). Estas características permiten clasificar al plutón de la GP como postectónico de emplazamiento forzado (Paterson y Tobisch, 1988).

En una etapa intermedia se produjo el desprendimiento del XKCN y la caída de éste en la masa de la cúpula de la GP. Conjuntamente, se produjo un basculamiento hacia el este (Fig. 14b y c). Las milonitas en el contacto occidental del XKCN presentan sentidos de movimiento consistentes con la caída del mismo. Asimismo, la foliación magmática del contacto oriental, con enclaves oblados de ejes principales paralelos a ella, son evidencias del flujo de magma en torno al XKCN durante su caída. Simultáneamente, se produjo un estiramiento de éste, acusado por una deformación coaxial evidenciada por la lineación de estiramiento, elongación de clastos en los conglomerados y aparición de grietas de tensión perpendiculares a la lineación, formación de 'boudinage', además de la generación de bandas de cizalle conjugadas oblicuas a la foliación.

En una etapa final, el XKCN se detuvo dentro de la masa viscosa de la GP. La presencia de pliegues mesoscópicos que afectan a la lineación se asocia a dicha detención. La sobreimposición de cataclasitas sobre las milonitas indica que el XKCN interactuó con la GP durante la etapa final de enfriamiento de este último (Fig. 14d).
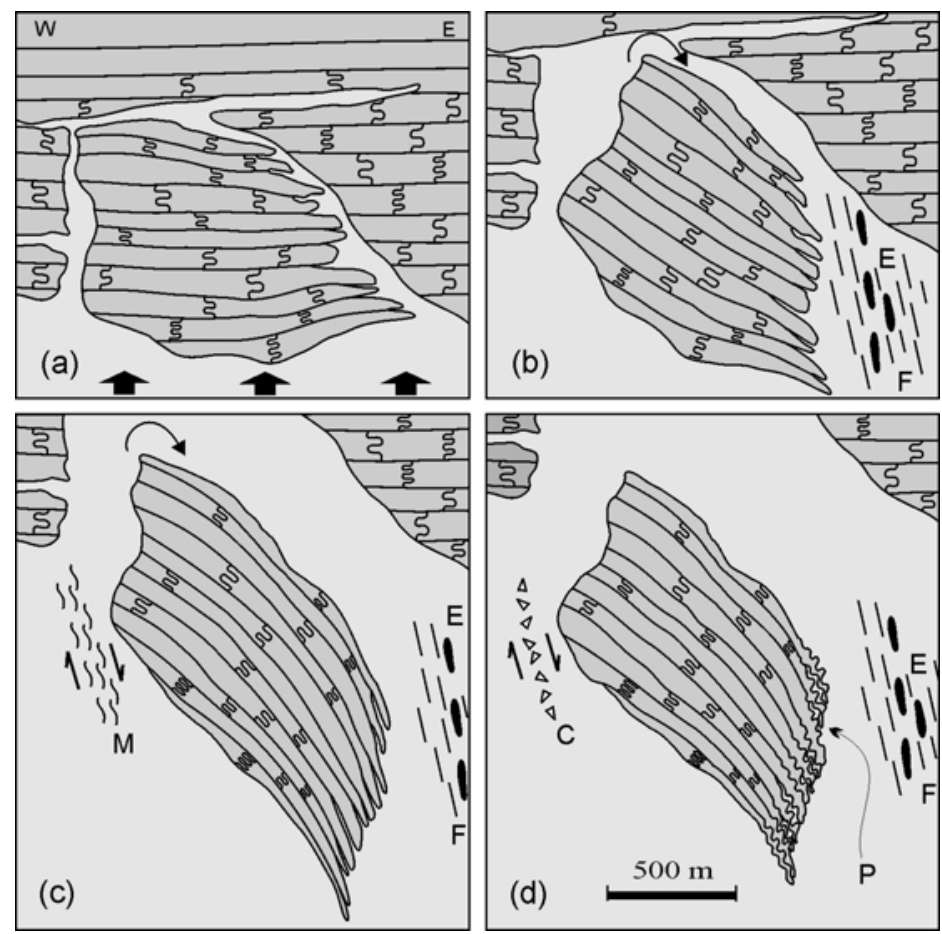

FIG. 14. Cuadro interpretativo de la evolución del XKCN desde su desprendimiento hasta su caída y detención en la cúpula de la GP, con su consecuente deformación y procesos asociados; (a)- el magma penetró en las fisuras de la roca de caja, aislando el xenolito. El flanco oriental de éste presenta mayor interacción con el magma. Este último ejerció una fuerte compresión hacia arriba, indicada por las flechas gruesas; (b)- basculamiento del xenolito hacia el este. Los enclaves, E, se deformaron y orientaron según el flujo de magma, indicado por la foliación, F, en el borde oriental del xenolito; (c) - el xenolito se estiró y continuó su basculamiento al este. En su borde occidental se generaron milonitas, $\mathrm{M}$; (d)- se formaron pliegues, $\mathrm{P}$, en el borde oriental del xenolito. Cataclasitas, C, se sobreimpusieron sobre la zona de milonitas. 


\section{AGRADECIMIENTOS}

Se agradece el financiamiento por parte de la Dirección de Investigaciones y Posgrados de la Universidad Católica del Norte, Chile. Esta contribución se benefició con la revisión de J.M. Tubia (Universidad del País Vasco, España), y de C. Arévalo y M. Suárez (Servicio Nacional de Geología y Minería, Chile). La mayoría de los dibujos fue realizada por L. Jofré (Departamento de Ciencias
Geológicas, Universidad Católica del Norte). Los dos primeros autores agradecen la compañía en terreno de C. Solís (Departamento de Ciencias Geológicas, Universidad Católica del Norte). El primer autor agradece a $\mathrm{C}$. Pérez de Arce y a $\mathrm{A}$. Tomlinson (Servicio Nacional de Geología y Minería, Chile) la correspondencia mantenida en torno a la edad de la Granodiorita Pinchal.

\section{REFERENCIAS}

Aguilar, A.; Niemeyer, H. 1984. Una zona de falla activa desde el Paleozoico inferior hasta el Neógeno en Quebrada Sama, al norte de Chuquicamata. Región de Antofagasta. Universidad de Chile, Departamento de Geología, Comunicaciones (34): 25-35.

Berthé, D.; Choukroune, P.; Jegouzo, P. 1979. Orthogneiss, mylonite and non coaxial deformation of granites: the example of the South Armorican Shear Zone. Journal of Structural Geology 1 (1): 31-42.

Best, M.G. 2003. Igneous and Metamorphic Petrology. edición No. 2. Oxford Blackwell Science: 729 p.

Breitkreuz, C. 1986. Das Paläozoikum in den Kordilleren Nordchiles $\left(21^{\circ}-25^{\circ} \mathrm{S}\right)$. Tesis de Doctorado (Unpublished), Institut für Geologie und Paäeontology, Technische Universität Berlin, Geotektonische Forschungen 70 (1-2): 1-88.

Bucher, K.; Frey, M. 2002. Petrogenesis of Metamorphic rocks. Springer-Verlag: $341 \mathrm{p}$.

Fry, N. 1979. Density distribution techniques and strained length methods for determination of finite strains. Journal of Structural Geology 1: 221-229.

Gapais, D.; Barbarin, B. 1986. Quartz fabric transition in a cooling syntectonic granite (Hermitage Massif, France). Tectonophysics 125: 357-370.

Griem-Klee, S.; Niemeyer, H. 2005. Provenance and age of metasedimentary basement rocks exposed in the Sierra de Moreno, northern Chile ( $\left.21^{\circ} 30^{\prime} \mathrm{S}, 68^{\circ} 50^{\prime} \mathrm{W}\right)$. Preliminary results. In Gondwana 12 Conference. Geological and Biological Heritage, Abstracts: 184. Mendoza

Huete, C.; Maksaev, V.; Moscoso, R.; Ulriksen, C.; Vergara, H. 1977. Antecedentes geocronológicos de rocas intrusivas y volcánicas en la Cordillera de Los Andes comprendida entre la Sierra Moreno y el Río Loa, y los $21^{\circ}$ y $22^{\circ}$ lat. Sur, II Región, Chile. Revista Geológica de Chile (4): 35-41.

Lisle, R.J. 1977. Estimation of the tectonic strain ratio from the mean shape of deformed elliptical markers. Geologie en Mijnbouw 562: 140-144.

Marre, J. 1982. Méthodes d'analyse structurale des granitoides. Bureau de Recherches Géologiques et Miniéres, Manuels et Méthodes (3): 128 p.

Nava, M. 2004. Interacción entre el Roof-pendant Pinchal y el Plutón Pinchal, en el extremo centro-sur del Cuadrángulo Cerro Yocas, Sierra de Moreno, Il Región de Antofagasta, Chile. Memoria de Título (Inédito), Universidad Católica del Norte, Departamento de Ciencias Geológicas: 108 p.

Niemeyer, H.; Venegas, R.; Baeza, L.; Soto, H. 1985. Reconocimiento geológico del sector sur-occidental del Cuadrángulo Cerro Yocas, ubicado en la zona de falla Quebrada Blanca-Chuquicamata, Región de Antofagasta. In Congreso Geológico Chileno No. 4, Actas 4: 1-629-1-653. Antofagasta.

Passchier, C.W.; Trouw, R.A.J. 1996. Microtectonics. Springer-Verlag: $289 \mathrm{p}$.

Paterson, S.R.; Vernon, R.H.; Tobisch, O.T. 1989. A review of criteria for the identification of magmatic and tectonic foliations in granitoids. Journal of Structural Geology 11 (3): 349-363.

Paterson, S.R.; Okaya, D.A. 1999. Why Don't See More Stoped Blocks in Plutons?: Results From ThermalMechanical Modeling. American Geophysical Union: T31A-30.

Paterson, S.R.; Tobisch, O.T. 1988. Using pluton ages to date regional deformations: Problems with commonly used criteria. Geology 16: 1108-1111.

Piazolo, S.; Passchier, C.W. 2002. Controls on lineation development in low to medium grade shear zones: a study from the Cap de Creus peninsula, NE Spain. Journal of Structural Geology 24: 25-44.

Platt, J.P.; Vissers, R.L.M. 1980. Extensional structures in anisotropic rocks. Journal of Structural Geology 2 (4): 397-410

Ramsay, J.G. 1967. Folding and Fracturing of Rocks. McGraw-Hill Book Company: 568 p.

Ramsay, J.G.; Graham, R.H. 1970. Strain variation in shear belts. Canadian Journal of Earth Science 7: 786-813.

Ramsay, J.G. 1982. Rock Ductility and its Influence on 
the Development of Tectonic Structures in Mountain Belts. In Mountain Building Processes (Hsü, K.J.; editor). Academic Press: Chapter 1-9.

Ramsay, J.G.; Huber, M.I. 1983. The Techniques of Modern Structural Geology: strain analysis. Academic Press: $307 \mathrm{p}$.

Simpson, C.; Schmid, S.M. 1983. An evaluation of criteria to deduce the sense of movement in sheared rocks. Geological Society of America, Bulletin, 94: 12811288.

Thorpe, R.; Brown, G. 1985. The Field Description of Igneous Rocks. Open University Press: $154 \mathrm{p}$.

Manuscrito recibido: Septiembre 10, 2004; aceptado: Octubre 5, 2005
Van der Molen, I.; Paterson, M.S. 1979. Experimental deformation of partially-melted granite. Contribution to Mineralogy and Petrology 70: 299-318.

Venegas, R.; Niemeyer, H. 1982. Noticia sobre un probable Precámbrico sedimentario-metamórfico en el borde occidental de la Puna, al norte de Chuquicamata. In Congreso Geológico Chileno No. 3, Actas 3: F 143F 154. Concepción.

Yardley, B.W.D.; MacKenzie, W.S.; Guilford, C. 1990. Atlas of metamorphic rocks and their textures: Longman, Scientific and Technical. John Wiley and Sons: $120 \mathrm{p}$. 